\title{
Towards a Robust Electronic Agriculture Platform Development
}

\author{
Aweh Opan ${ }^{1}$, Tope-Oke Adebusola ${ }^{2}$, Atolagbe Luqman ${ }^{3}$ \\ ${ }^{1}$ Afe Babalola University, Ado-Ekiti, Ekiti State.opaniaweh@gmail.com \\ ${ }^{2}$ Afe Babalola University, Ado-Ekiti, Ekiti State.topeokea@ abuad.edu.ng \\ ${ }^{3}$ Afe Babalola University, Ado-Ekiti, Ekiti State.laas1299@gmail.com
}

\begin{abstract}
This study identified that the calls to go back to agriculture has reached high decibels and in response several individuals and institutions have shown inclinations towards these calls. The study also identified that agriculture has become knowledge intensive, such that timely, accurate and specifically tailored information have become critical determinant success factors. To aid those disposed to responding to these calls as well as the requisite critical information needs germane to achieving success, the study looked in the direction of Electronic agriculture (Electronic-Agriculture), an emerging research area. And in specific terms, the study analyzed the requirement specifications incidental to meeting the information needs of the identified challenges. And based on the insights gained, the study modeled and simulated a system whose features and functionalities met the requirements for a desirable conceptual framework for setting up an Electronic -Agriculture platform.
\end{abstract}

Key words: Information Technology, Electronic Agriculture, Farming, Platform, Modelling.

\section{INTRODUCTION}

Agriculture is increasingly navigating the knowledge route, such that access to appropriate, accurate information personalized to specific locations and conditions is pivotal to resources optimization by farmers amidst changing circumstances.

Against the backdrop of the positive impact of Information Technology on virtually all spheres of human endeavors the Food and Agricultural Organization (FAO) and the International
Telecommunication Union (ITU) have spearheaded the development and deployment of IT in the Agriculture sector (otherwise described as Electronic -Agriculture), as a means of achieving food security and other millennia development goals (MDGs).

\section{Electronic -Agriculture}

Electronic -Agriculture has been described as an emerging field focusing on the enhancement of agricultural and rural development through improved information and communication processes. Electronic -Agriculture involves the conceptualization, modelling, development, appraisal and application of pioneering ways to use information and communication technologies (IT) in the rural domain, with a keyemphasis on agriculture[1][2]. From a technical and economic perspective, it is a new area of knowledge emerging out of convergence of IT and farming techniques[3].

Electronic -Agriculture like any other innovation isexpectedto change in scope and evolve as the understanding of its requirements grows. It holds the great potential to promote sustainable agriculture while protecting the environment and finding an effective way to feed the world's population. Electronic -Agriculture holds a wide range of solutions to some agricultural challenges.

Setting in place a national electronic -Agriculture framework is an essential first step for any country planning on using IT for agriculture. While the need for Electronic -Agriculture strategies is acknowledged by many stakeholders, most countries are yet to adopt a strategic approach to making the best use of IT developments in agriculture. Electronic -Agriculture strategies will help to explicate both monetary and social resources, and address 
holistically the IT opportunities and challenges of the agricultural sector while generating new revenues and improving the lives of people in rural communities. It will also help ensure that the goals of national agricultural plans are achieved [4].

Like all strategies and plans, the outcomes of these processes are not static and changes in a country's strategic context will require a dynamic approach to updating the strategy so that it remains relevant. Adopting a national approach to Electronic Agriculture will result in improved livelihoods and incomes for people living in rural communities [5].

It is strongly believed that Electronic -Agriculture would save farmers and nations large sums of money through the efficiencies that would be introduced into the processes of different farm operations as Electronic -Agriculture evolves in scope leading to harnessing of IT applications in the agriculture sector.

\section{Motivation for this Study}

In the recent past, the call by government, international/local organizations as well as individuals to go back to agriculture has reached high decibels. In response to this call, there is a growing interest in agriculture by several organizations, governments and individuals. These calls cannot be isolated from the numerous information requirements required for output to be high. For example, the farmers or prospective farmers need good information about weather, state-of-the-art farming techniques, seedlings origin, current research findings, funding sources, product markets, management techniques to mention a few.

Already, money have been voted to farmers by the government so as to boost output. It is only imperative that such governments should keep track of these farmers and the support provided. In addition to providing these types of support, these governments should be able to provide easy access to vital information regarding a great agricultural practice.

Meeting these budding needs and other contingent ones that may arise in due course requires the development of a robust Electronic -agricultural framework

\section{Thrust of this Study}

The modelling and simulation of an integrated information platform which by default constitutes the core of any E-agricultural strategy is the thrust of this study. And the study approaches this task by developing a comprehensive platform for agriculture related information, and a database for farmers and other institutions that provides farming related support services. The platform will aggregate information from different agencies, such as financial, research and geophysical institutions, consultants and individuals/groups. The platform also had the capability to pull and push electronic mail (e-mail) and simple message service (SMS) based communication services.

\section{RELATED LITERATURE}

\section{The Terminology Electronic -Agriculture}

While the [1] and the [2] articulation of the terminology Electronic -Agriculture is largely regarded as authoritative, a perusal of sundry other literature introduces some forms of nuances, apparently based on the backgrounds from which such authors have approached the subject. These nuances or slight variations in perception will become evident as the study discusses the contributions of some of these authors. Overall, there is consensus on what the terminology Electronic Agriculture denotes, its prospects on agricultural productivity as a whole and it enabling technologies

\section{Need for Electronic -Agriculture Development}

Electronic -Agriculture has become pertinent because agriculture in contemporary times have become increasingly knowledge-intensive and today's farmers live in a challenging milieu [6]. There is a continuing need to provide the right information to the people who need to make the decisions that make the difference to their livelihoods and to ensure food security for the ever-growing population. Providing such knowledge can be challenging, because the highly localized nature of agriculture requires that information must be tailored specifically to distinct conditions [7][4]. In support of the increasing knowledge requirement in agriculture, [8],[9] and [10]observed that IT remains the key driver and facilitator in connecting the actors along agricultural value chains and in disseminating critical information to large populations on the need to sustainably secure the food and nutrition requirements. As Mao [11] succinctly put it: "Information of adequate quality is a necessary condition for improvement of all areas of agriculture". And at a somewhat different level, Electronic -Agriculture enhances the agricultural 
value chain through better access to information which in turn increases productivity, better access to changes in price in different markets, provision of prompt information on policies and programs of government schemes for farmers, while remaining abreast of innovations in agriculture [3].[9] rightly observed that there has been renewed emphasis on promoting agricultural production as well as food and nutrition security. Consequently, he further reported that the demand for, and supply of food, will continue to be affected by population growth, rapid urbanization, shifts in dietary patterns, and climate change. He therefore added that improving agricultural production is likely to remain high on the policy agenda of governments for the conceivable future.

\section{Electronic -Agriculture Infrastructure Provisioning}

The indispensability of Electronic -Agriculture has been established and its requisite support infrastructure requirements specifications are not farfetched. There are however arguments on who should provide and manage these types of knowledge intensive infrastructures. [12] argues that government has always played an essential role in agriculture development, implying that governments are better placed to provide and ensure the proper management of such infrastructure. Mittal and Mehar [13] however, have a different view and they identified three categories of funding which they classified as government-led, market driven, and community selfsupport.

Considering the fact that agricultural information dissemination service is one of the critical missions in implementing Electronic-agricultural [14][15][16], it is imperative to bring diverse participants to invest substantial volumes of effort and money into the expansion and distribution of innovative and effective information dissemination models [14]. On this premises, the Mittal and Mehar model [13] is advocated.

However, the development of such models must take into cognizance some inhibitions to leveraging IT in agriculture as explained by [17] and Mittal [18]. These include:

i. Unawareness about the benefits of IT: this unawareness is especially serious in rural communities where network and internet services are lacking.

ii. Uncoordinated Efforts to Address Bandwidth Problems: farmers and organization needs government backing to afford the required platforms across farming communities. The efforts required to achieve this needs to be properly coordinated.

iii. Absence of Required Skill and Education: The facts and expertise obligatory to effectively use IT facility for agricultural efficiency is infinitesimal and, in some cases, missing.

iv. Unavailability of Requisite Information: Another major problem to using IT in agriculture is the unavailability of information to be accessed to address some situations, even when all the needed information access infrastructure are in place. Research findings are not uploaded for access, credit sources information is not known to the farmers, weather/climate information for the specific regions are not posted, quality seedling, equipment, pests/disease control strategies and other vital information are not available for retrieval and use by farmer.

Electronic -Agricultural Information Provisioning Information provisioning remains the central feature of any E-agricultural strategy, consequently it is germane to explore the information types that can be provisioned and harnessed from investments in them. [19] noted that there has been a notable evolution in the use of IT in African agriculture, especially in the area of access to market information and dissemination of agricultural information to farmers. They noted further that farmer's information services at both the national and regional level are a promising new field of research and application in the emerging field of Electronic -Agriculture. [20] observed that IT have helped to transform the Chinese agricultural sector. In their study which reviewed and presented seven IT based information dissemination models, 
and the resulting success cases, they provided useful directions for researchers and practitioners who may be saddled with developing IT based information dissemination systems for their countries or states. [21] is of the view that the economic potential of IT use in agriculture is not fully utilized. The study presented examples to include precision farming and livestock management where IT could facilitate more efficient decision making not only for managers of enterprises related to agriculture, but also for policy makers as well. [22] notes that smartphones have become a useful tool in agriculture because their mobility matches the nature of farming, the cost of the device is highly accessible, and their computing power allows a variety of practical applications to be created. Moreover, smartphones are nowadays equipped with various types of physical sensors which make them a promising tool to assist diverse farming tasks. [23] presented an elaborate summary of the information types that farmers desire to include the following:

i. Information on crops: such as categories of seeded crops, size of land to accommodate specific size of crops, time to plant seeds, time to harvest, how to ensure good yields etc. It is assumed that farmers can make their own production plans based on this information.

ii. Information on production techniques: Research reports agricultural institutes or other related agencies or individuals that can lead to improved production.

iii. Information on production equipment and agricultural inputs: Modern equipment and how and where they can be accessed and used and other facilities for pests and disease control and any other inputs that will improve yield should be readily accessible to farmers

iv. Market information: The locations and the means for farmers to get better prices for their produce is another vital information to be communicated to farmers. To further support farmers in gaining the best prices for their products, information on market review of prices of various agricultural products should be available so that the appropriate time and place to market products can be determined

v. Other information of interest: Examples of such information includes weather forecast, credit facilities, and expert's advice about maintaining crops in healthy state. There is no doubt that improved information flow will have positive effect on the agricultural productivity, but gathering and distribution of information is difficult and expensive. IT offers some level of solution to these problems. It can help to disseminate and to receive information to and from farmers in any location, including remote ones.

\section{Innovations in Electronic -Agriculture}

[24] presented a generic framework for ElectronicAgricultural system comprising of knowledge management and a monitoring system to help farmers keep up with important information that will assist them to increase their productivity. [25] reviewed two theories of innovation and from their findings they came up with an innovative approach to leveraging IT in agricultural (Electronic Agriculture). In the first step, they explored the problem of IT adoption in agriculture, while in the second step, they proposed a theory of Electronic Agriculture adoption and innovation.

The need to continue to innovate to bring Electronic Agriculture to maturity is imperative as technology itself, advances. [23]identified that IT can have a direct and an indirect impact on agriculture. Direct impact comes from the use of IT for accessing information that is consumed directly, while the indirect impact results from its use in quality decision arising from the decision support systems of management functions.[26] noted that the incorporation of IT into farming involves the integration of diverse technologies, with each capable of positively impacting the efficiency of farming activities, thereby promoting sustainable agricultural practice. All these technological innovations will help farmers to be more productive and contribute 
immensely to the improvement of their life quality and that of the society in general [27],[9],[28].While all these technological innovation will aid agriculture, [29] expresses a concern regarding deforestation and encroachment on reserved terrain and proposed an intelligent framework for deforestation detection and control system using machine learning algorithm and wireless sensor network, that take proactive and reactive measures to curb deforestation. The data gathered can also be made available on the robust electronic agriculture platform to guide farmers regarding the farming landscape.

\section{MATERIALS AND METHODS}

The system development concept and modelling, the actual system implementation and the system testing results, as shown by screen shots of running application is presented in this section.

\section{System Development Concept and Modelling}

This study was basically concerned with modelling and simulating a one stop shop information platform for various agriculture related information. The intended platform will be equipped with email and SMS pull and push messaging services. The approach that was used therefore, was to develop a portal that enabled the information of users (farmers and prospective farmers and others) to be stored such that emails and SMS based requests and messages about weather, improved seedlings, new farming techniques, loan/grant facilities, new research findings/innovations, products marking information etc. could be pulled or pushed to them. The system was required to permits two-way information flow between the relevant third-party agencies responsible for the primary information production and management and the platform. The platform was also required to support some further processing using its inherent software and hardware facilities to store and to make the information accessible to user mobile devices.

To gain a better insight into the requirements specification and the design of this system, the research approaches of document perusal and personal interviews (consultation with others) was used. And from the knowledge gained, a context diagram was drawn to depict the high-level representation of the system. Figure 1 shows this high-level representation of the system (platform)

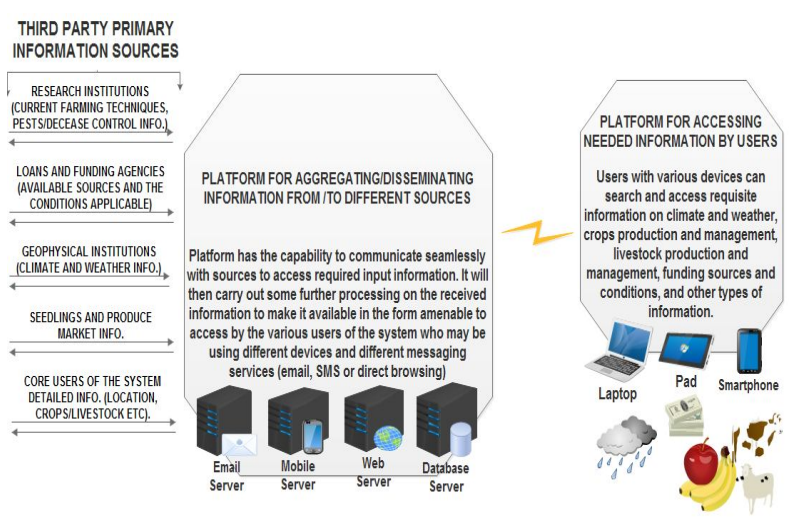

Figure 1: Context Diagram of Integrated Agriculture Information System

The extreme left end of the figure shows the primary agencies responsible for feeding the platform with requisite information. The middle polygon depicts the platform and its required processes and some of the software and hardware facilities required to accomplish its purposes. The extreme right polygon and its associated devices and other objects illustrates some of the information accessible from the platform.

\section{System Implementation}

The conceptualized platform was implemented as a Web portal using the common three tier approach that partitions the whole system into front end, middle end and back end.

As contained in the context diagram (figure 1), the system database management system was implemented using MySQL database management system. Apache tomcat Web server was used to hold the Web applications, while the mail and mobile servers were implemented using third parties mail and SMS entry applications. These applications constitute the platform's backend systems. As parts of the platform processing requirements, a set of programming/scripting languages were used to implement the system middle end features, which is often referred to as the system business logic. The Hypertext Preprocessor (PHP) was used extensively to implement the system features; Hypertext Markup Language 5 (HTML5) was used to design the web pages to make them responsive so as to fit properly into different devices that will be used to accessing 
information; Cascading Style Sheet (CSS) was used to implement very few features of the system; and JavaScript (JQuery): was used to implement the popup menus in the system

In three tier web applications design, the front end displays the graphical user interfaces generated by the middle end applications. This was depicted by the mobile devices attached to the right polygon in Figure 1.

\section{System Testing}

Having attained a good level of performance in the system development and testing cycle, some of the system features were isolated for properly tested for some desirable functionality. The few features so isolated are presented next. Figure 2 shows the running system window for the farmers. Here the demographic details of the farmer such as name, farming specialty, phone number is captured and stored in the system database. On the left column there are other links that the user can explore the Geo Zone, Loan management and research material links.

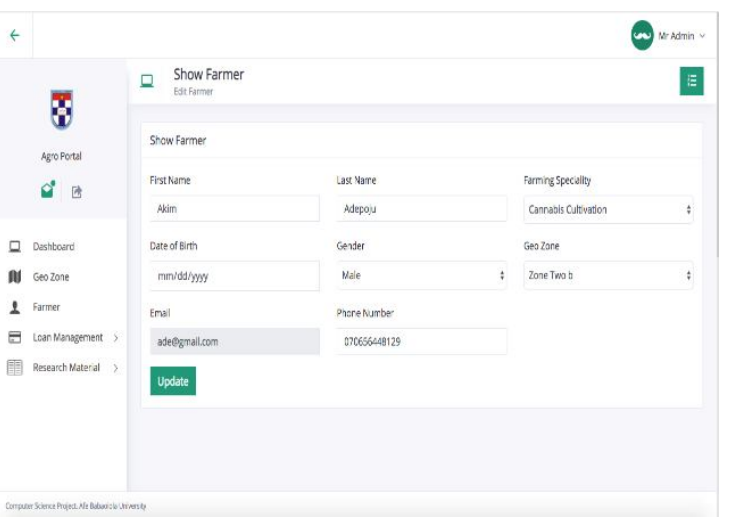

Figure 2: Sample User Records

Figure 3 shows the loan management window. Here, the farmers can access different loan sources and apply for loan. The farmer will complete the loan application form and submit it. The loan body who also access the system can view all the submitted forms and shortlist the farmers that will receive the loan.

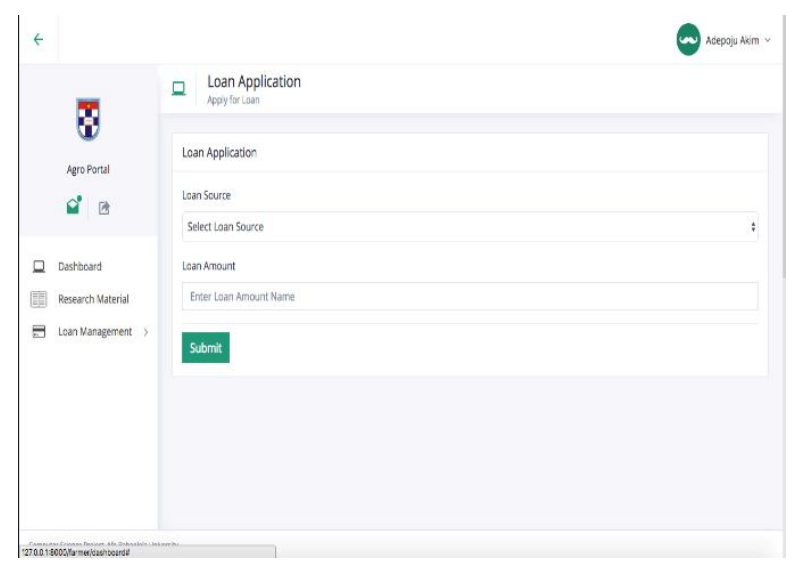

Figure 3: Loan Application Window

\section{CONCLUSION}

The emerging information intensive approach to agriculture (Electronic -Agriculture) requires keen attention because it is already yielding good results in some countries, notably China and Malaysia that have committed resources to its development. It is strongly believed that Electronic -Agriculture will save farmers and nations large sums of money through the efficiencies that will be introduced into the processes of different farm operations.

Although, the required hardware and software facilities for developing the supporting Electronic Agriculture infrastructure appears identical across different countries, but each country, hadto develop their own models to suit their peculiar environment. Therefore, in the absence of a standardized model of Electronic -Agriculture platforms, different nations must develop models that reflect their environmental background.

This is precisely what this study has attempted to accomplish by modelling and simulating such an infrastructure. The study is important to those aspiring to heed the calls to return to farming. They can access veritable information and then learn much about their intended areas of interest in farming and all other needs such as funding-, markets-, short- and long-term weather conditions to name a few.

The government through its ministry of agriculture, especially its extension services workers can use this platform for seamless information exchanges with both urban and rural farmers, providing them with all needed information on current agricultural practices such as pests and disease control and rainfall patterns 
In the course of this study, it was observed that most state governments were providing huge financial supports to some farmers. Such farmers could be registered on this kind of platform so that in addition to monitoring their progress, government can encourage their productivity by furnishing them with accurate timely relevant information.

The factors that have driven productivity in agriculture in the time past have been described as bid and demand. Currently, it can still be argued that the driving force behind agricultural productivity is demand, but this study wish to contribute to this debate by arguing that both demand and information technology is the joint, current driver now and will extend into the far future. Therefore, pertinent information must reach the target users promptly. Information on improved seedlings, modern techniques of cultivation, weather forecasts, nutrients, pests/diseases control, loan/farming support schemes, improved produce handling techniques, markets for produce etc. All these are critical factors for increased productivity, and its concomitant sustainable development from the perspective of agricultural productivity.

\section{REFERENCES}

[1]Food and Agricultural Organization (FAO) (2013). Electronic -Agriculture Strategy. http://www.fao.org/fileadmin/user_upload/kce/Doc_f or_Technical_Consult/ELECTRONIC

AGRICULTURE _-_English.pdf (accessed 09$10=2017$ )

[2] Chauhan R. M. (2017) Advantages and Challeging in E Agriculture. Orient. Journal of Computer Science and Technology, Vol. 8(3). Available from: http://www.computerscijournal.org/?p=2966

[3]INSIGHTS(2014). E-technology in the Aid of the Farmers, Insights Active Learning Press, India.

[4] Food and Agriculture Organization (FAO) and International Telecommunication Union (ITU) (2016). Electronic -Agriculture Strategy Guide
Piloted in Asia-Pacific Countries, FAO and ITU Publication, Bangkok.

[5] Miller (2013). Agriculture and information and communication technology, World Bank Report on ICT in Agriculture, World Bank.

[6] Mohamad, M. R. A. and Gombe, M. I. (2017). electronic -Agriculture revisited: a systematic literature review of theories, concept, practices, methods, and future trends, in: British Academy of Management Annual Conference, 5-7 September 2017, Warwick Business School, UK.

[7]World Bank (2011). ICT in agriculture: Connecting smallholders to knowledge, networks, and institutions. http://www.fao.org/fileadmin/user_upload/kce/Doc_f or_Technical_Consult/ELECTRONIC

AGRICULTURE_-_English.pdf (accessed 09-102017)

[8] Abswaidi, R., Anael, S. and Khamisi, K. (2017). Analysis of factors influencing information access, among rural communities in Tanzania, Journal of Agricultural Extension and Rural Development, Vol. 9(9), pp. 196-201,

[ 9 ]Atiba P. (2013). electronic -Agriculture in the Caribbean - A Concept Come of Age, Trinidad and Tobago Chamber of Industry and Commerce, Contact, Vol.13(1), pp28-29.

[10] McNamara, K., Belden, C., Kelly, T, Pehu, E., Donovan, K. (2011): ICT in agricultural development,ICT in Agriculture - Connecting Smallholders to Knowledge, Networks, and Institutions, The International Bank for Reconstruction and Development/The World Bank, Washington, pp. 3-14.

[11] Mao, Y. (2012). Meaning and mode of mobile information services, Inf Sci, 2

[12] Liu X. (2010). Reflections on the development of agricultural informatization. In Chinese. In Chinese. Silicon Valley; pp. 1671-7597.

[13] Mittal S, Mehar M. (2015). An assessment of farmer's information networks in India-role of modern ICT. CGIAR.org. Link: http://www.afita.org/graph/web_structure/files/Semin $\operatorname{ar} \% 20(07)-02(1) . p d f$. 
[14] Li, D. (2009). China rural informatization development 2009 report, Publishing House of Electronics Industry, Beijing

[15] Chen, X. (2012). Introduction to agricultural informatization, China Agriculture Press.

[16] Lin, Y. P., Petway, J.R., Anthony, J., Mukhtar, H., Liao, S. W., Chou, C. F. and Ho, Y. F. (2017). Blockchain: The Evolutionary Next Step for ICT Electronic -Agriculture. Environments, Vol. 4(50).

[17] Rao, S.S. (2003): Information Systems in Indian Rural Communities, Journal of Computer Information Systems, Vol. 44(1), pp. 48-56.

[18]Mittal, S.C. (2012): Role of Information Technology in Agriculture and its Scope in

India, Available at: http://125.19.12.220/applications/Brihaspat.nsf/6dca4 9b7264f71ce

65256a81003ad1cb/82f2c15ccd4dd9a065256b37001 af3fe/\$FILE/it_fai.pdf

[19]Gakuru, M., Winters, K. and Stepman, F. (2009). Innovative Farmer Advisory Services using ICT, W3C Workshop "Africa Perspective on the Role of Mobile Technologies in Fostering Social Development", Maputo, Mozambique.

[20]Zhang, Y., Wang, L. and Duan, Y. (2016). Agricultural information dissemination using ICTs: A review and analysis of information dissemination models in China, Journal of Information Processing in Agriculture, Vol. 3(1), pp. 17-29

[21] Phougat, S. (2006): Role of Information Technology in Agriculture, Science Technology Entrepreneur, pp. 1-7.

[29]Ibam, E. and Olowokere ,V.(2021).A Smart Deforrestation Monitoring and Control System model. International Journal of Advance Trends in Computer Science and Engineering,Vol. 10(3), pp. 1901 1913.https://doi.org/10.30534/ijatcse/2021/58103202 1
[22]Pongnumkul, S., Chaovalit, P. and Surasvadi, N. (2015). Applications of Smartphone-Based Sensors in Agriculture: A Systematic Review of Research, Journal of Sensors, Vol. 2015, pp 1-18

[23] Milovanović, S. (2014). The Role and Potential of Information Technology in Agricultural Improvement, Journal of Economics of Agriculture, Vol. 61(2), pp. 471-485

[24] Mohanraj, I. and Naren, J. (2016) An Architectural Framework for Electronic -Agriculture System, Proceedings of the INDIACom-2016 3rd 2016 International Conference on "Computing for Sustainable Global Development”, India.

[25]Somers, S and Stapleton, L (2012). Rethinking electronic -Agriculture Innovation Using a Human Centred Systems Lens,IFAC Proceedings, Vol. 45(10), pp. 97-102.

[26] Adeyemo, A. B. (2013). An e-farming framework for sustainable agricultural development in Nigeria. Journal of Internet and Information System, Vol. 3(1), pp. 1-9.

[27]Gorla, N. (2009): A Survey of Rural eGovernment Projects in India: Status and Benefits, Information Technology for Development, Vol. 15(1), pp. 52-58.

[28] Novković, N., Vasiljević, Z. and Matković, M. (2013). E-Concept of an Agricultural Extension Service, Agriculture \& Forestry / Poljoprivreda i Sumarstvo, Vol. 59()2, pp187-198. 